\title{
UK resident population by country of birth
}

In August 2008, estimates of the 'Population by country of birth and nationality' were published for the first time by the Office for National Statistics (ONS) from the Annual Population Survey (APS). Tables were published for the calendar years 2004 to 2007. This article provides an analysis of the published figures, and some background information about the APS.

\section{Introduction}

The Annual Population Survey (APS) ${ }^{1}$ is a sample survey primarily used to provide information on the UK labour market. In August 2008 estimates of the size and composition of the UK population by country of birth and nationality for the calendar years 2004 to 2007 were published for the first time. This article analyses the trends seen in the data at UK and regional level.

Estimates are discussed by country of birth only as they provide a more consistent picture of UK trends than nationality (see Box one).

The article begins by providing some background information about the APS and the techniques used to measure the reliability of the estimates. It then looks at the trends seen at UK level by country groupings (including the European Union) and the most common non-UK countries of birth.

The estimates are next investigated at Government Office Region (GOR) level, including an analysis of the trends seen in London, discussion of the increase in the number of non-UK born residents by GOR and an investigation into the most common non-UK country of birth in each GOR. The geographical distribution of Indian and Polish born residents is then analysed, followed by discussion of the age distribution of the Polish born within the UK.

Finally, the estimates are discussed at a lower geographical level, focusing on the size of the UK and non-UK born population in each London borough and the most common non-UK country of birth in each. Several places in the UK have experienced a decrease in the size of the UK born population and an increase in the size of the non-UK born population over the period, and an analysis of these areas is undertaken. 


\section{Box one}

Country of birth and nationality are both self-reported by respondents to the Annual Population Survey (APS). Someone with dual nationality may report either of their nationalities at interview as a person's nationality can change over time; however their country of birth is fixed.

There are two main reasons for differences between nationality and country of birth:

1. Those born abroad remaining in the UK often apply to become British nationals.

2. Many people born abroad have British nationality.

An example of reason 2 shown above is due to people whose parents were based abroad in the military services when they were born, as they may have British nationality but a foreign country of birth. For example, in the UK in 2007 there were:

- 89,000 German nationals (tenth most common non-UK nationality)

- 266,000 people who were born in Germany (fifth most common non-UK country of birth)

Of all the people born in Germany who were resident in the UK, 186,000 (70 per cent) were UK nationals. This could be explained in part by the forces bases in Germany.

Due to the accession of the A8 countries to the EU in May 2004 and the accession of the A2 countries (Bulgaria and Romania) in January 2007, the published tables, and therefore the time period analysed in this article, provide a glimpse of trends in the UK during this period of accession.

Table 1 provides an outline of the 'Population by country of birth and nationality' tables that are published online each quarter. This particular article analyses the 2004 to 2007 calendar years by country of birth.

\section{Data source}

The estimates provided in this article are taken from the APS. This is a sample survey which consists of the Labour Force Survey (LFS) ${ }^{2}$ plus various sample boosts. The APS was introduced in 2004 as a further improvement to the Local LFS (LLFS). This existed from 2000 to 2003 as an enhancement to the LFS to help improve labour market information at a local level. The APS then enhanced this for 2004 onwards by boosting the sample further in the urban areas of England in order to sample the economically active better.

The LFS is a household survey of people resident in the UK at private addresses. Between 2004 and 2007 it surveyed those who had been resident at the address for six months or more. The LFS does not

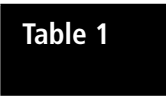

\section{Contents of online tables published quarterly}

\begin{tabular}{l|l|l}
\hline UK level & GOR level & $\begin{array}{l}\text { Unitary authority/ Metropolitan } \\
\text { borough/ London borough/ } \\
\text { County level }\end{array}$ \\
\hline $\begin{array}{l}\text { Broad country of birth / } \\
\text { nationality groups }\end{array}$ & $\begin{array}{l}\text { Broad country of birth/ } \\
\text { nationality groups }\end{array}$ & $\begin{array}{l}\text { UK/non-UK by country of birth/ } \\
\text { nationality }\end{array}$ \\
$\begin{array}{l}60 \text { most common foreign } \\
\text { countries of birth/ nationality }\end{array}$ & $\begin{array}{l}\text { Five most common } \\
\text { foreign countries of } \\
\text { birth/ nationality }\end{array}$ \\
\hline
\end{tabular}

\section{Box two}

Each quarter's LFS sample of 53,000 households is made up from five 'waves', each of approximately 11,000 households. Each wave is interviewed in five successive quarters, such that in any one quarter, one wave will be receiving their first interview, one wave their second and so on, with one wave receiving their fifth and final interview. Thus there is an 80 per cent overlap in the samples for each successive quarter and the sample is completely different after six quarters.

In some areas of the UK the boost makes up the bulk of the APS dataset, with a smaller contribution from the main LFS. The boost has a four year wave structure instead of the five quarter wave structure in the main LFS; after the initial interview, sampled households are interviewed three more times on an annual basis. Therefore the boost for these areas may be slower to react to a change in migration patterns than the main LFS, and the speed with which the APS sample responds to changes in the household population may vary across the UK.

APS datasets are produced quarterly with each dataset containing 12 months of data. There are approximately 360,000 persons per dataset. More robust estimates are available by using the APS than from the main LFS.

In 2007 the number of people interviewed who were UK born and non-UK born were 322,000 and 30,000 respectively. The number of people interviewed who were of UK and non-UK nationality were 334,000 and 19,000 respectively. The estimates produced by weighting these contacts are all considered precise in relation to their coefficient of variation (see Box three).

directly sample students in halls of residence as their parents are asked to respond by proxy. If the student has non-UK resident parents, they are not sampled at all. It also does not sample residents in most other communal establishments, such as hostels, hotels, prisons, and defence establishments. ONS is currently piloting a survey of communal establishments to identify people who are not interviewed in household surveys such as the APS. This survey aims to collect information about them to assess if such a survey can supplement our existing data sources in building a more complete picture of the UK population.

The main purpose of the LFS survey is to provide information on the UK labour market, but it includes data on a variety of other variables such as country of birth and nationality.

\section{Box three}

Standard error is a measure of uncertainty associated with making inferences from a sample. The coefficient of variation indicates the robustness of each estimate. It is defined as:

$$
\frac{\text { Standard error of the estimate }}{\text { Estimate }} \times 100
$$

A confidence interval provides an estimated range of values in which an actual data value is likely to fall. The confidence interval provided is a 95 per cent interval. This means that across the dataset as whole, the confidence intervals are expected to contain the true values around 95 per cent of the time. It is obtained as:

\section{$1.96 \times$ standard error}


The APS combines results from the LFS and the English, Welsh and Scottish LFS boosts. These boosts increase the size of the sample and therefore provide more robust estimates. Box two describes the way in which the APS is conducted.

Box three explains the coefficient of variation and confidence intervals, which are provided on the published tables to indicate the accuracy of each estimate.

\section{Trends at UK level}

Figure 1 shows the estimated size of both the UK and non-UK born population of the UK for the period 2004 to 2007.

The size of the UK born population has remained constant throughout the four year period at around 54 million. In contrast, the non-UK population has increased from an estimated 5.2 million in 2004 to 6.3 million in 2007 , an increase of 21 per cent. In 2004, an estimated 8.9 per cent of the total population was non-UK born; by 2007 this had increased to 10.6 per cent.

The UK-level estimates can be broken down to investigate the non-UK born population by country of birth groupings. An explanation of these groupings can be seen in Box four.

Table 2 shows the estimated number of non-UK born residents of the UK in both 2004 and 2007 by certain country of birth groupings, along with the corresponding percentage of all non-UK born residents.

\section{Figure 1 \\ Numbers of UK born and non-UK born in the UK} population, 2004-07

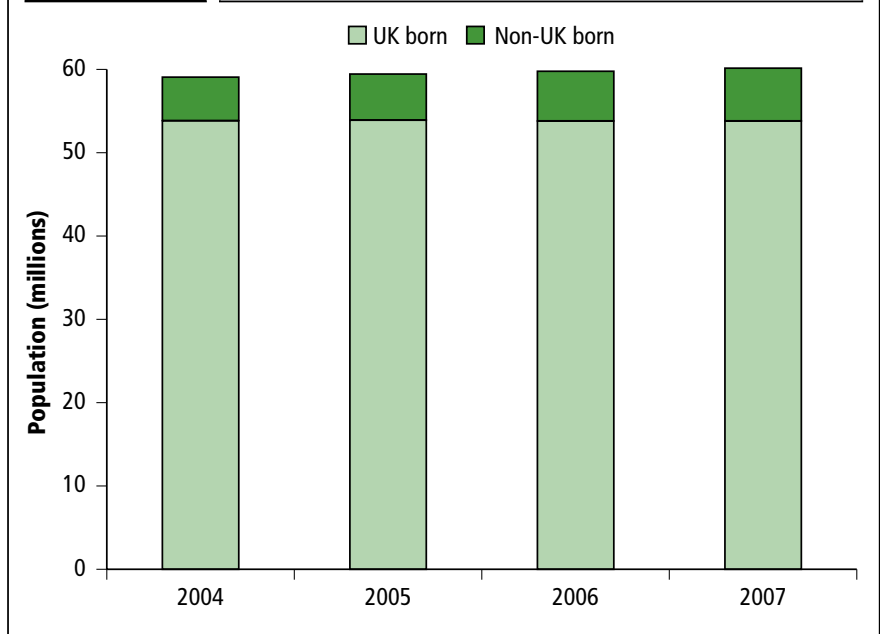

\section{Table 2}

Non-UK born residents of the UK 2004-2007, by country of birth grouping (thousands)

\begin{tabular}{l|c|c|c|c}
\hline \multirow{2}{*}{ Country of birth groupings } & \multicolumn{2}{|c|}{2004} & \multicolumn{2}{c}{2007} \\
\cline { 2 - 5 } & Estimate & $\%$ & Estimate & $\%$ \\
\hline Republic of Ireland & 452 & 9 & 420 & 7 \\
EU13 & 768 & 15 & 832 & 13 \\
A8 & 167 & 3 & 589 & 9 \\
Other & 3,741 & 71 & 4,373 & 69 \\
Total non-UK & 5,233 & 100 & 6,342 & 100
\end{tabular}

Notes: Totals may not sum due to rounding

The coefficient of variation of each of these estimates falls between 0 and 5 , which means that these estimates are considered precise.

\section{Box four}

United Kingdom The Channel Islands and the Isle of Man are
included.

European Union 13 Includes the countries of the EU, other than (EU13) the UK and Republic of Ireland, as constituted between 1 January 1995 and 1 May 2004 (i.e. Austria, Belgium, Denmark, Finland, France, Germany, Greece, Italy, Luxembourg, Netherlands, Portugal, Spain and Sweden).

European Union A8 These are the eight Central and Eastern European (A8) countries that acceded to the EU on 1 May 2004 (Czech Republic, Estonia, Hungary, Latvia, Lithuania, Poland, Slovakia and Slovenia).

European Union 26 These are all of the countries of the EU, excluding (EU26) the UK, as constituted on 1 January 2007. They include the Republic of Ireland, the EU13 and A8 groups plus Cyprus, Malta, Bulgaria and Romania.

Other

This is defined as all those countries not in the UK or EU26 groups.
The estimated number of UK residents born in all country groupings apart from the Republic of Ireland has increased over the four year period, with the most notable increase occurring to those born in the A8 (an increase of 423,000).

The estimated number of EU26 born UK residents increased by 477,000, or 32 per cent, between 2004 and 2007. This was driven by the increase in the number of A8 born residents over the four year period. Of this increase, an estimated 311,000 Polish born people made up 65 per cent of the overall EU26 increase.

The most common non-UK country of birth in the UK in each year was India. In 2004 there were an estimated 502,000 Indian born residents in the UK, and by 2007 this had increased to 613,000. In both 2004 and 2007 Indian born residents made up just less than 10 per cent of the nonUK born population. Table 3 shows the five most common countries of birth in the UK in 2004 and 2007.

In 2007, Poland was the third most common non-UK country of birth in the UK, as can be seen in Table 3, representing an estimated 6 per cent of the non-UK population. This was an increase from 2 per cent $(95,000)$ in 2004 , when it was the 12 th most common non-UK country of birth.

\section{Table 3}

Five most common non-UK countries of birth in the UK, 2004 and 2007 (thousands)

\begin{tabular}{l|l|c|l|c}
\hline & \multicolumn{2}{|c|}{2004} & \multicolumn{2}{c}{2007} \\
\cline { 2 - 5 } & Country & Estimate & Country & Estimate \\
\hline 1 & India & 502 & India & 613 \\
2 & Republic of Ireland & 452 & Republic of Ireland & 420 \\
3 & Pakistan & 281 & Poland & 405 \\
4 & Germany & 275 & Pakistan & 377 \\
5 & Bangladesh & 225 & Germany & 266 \\
\hline
\end{tabular}

Note: The coefficient of variation of each of these estimates falls between 0 and 5 , which means that these estimates are considered precise. 
The estimated number of UK residents born in the Republic of Ireland decreased between 2004 and 2007 from 452,000 to 420,000. The estimated number born in Germany also fell slightly from 275,000 to 266,000 .

\section{Trends at Government Office Region (GOR) level}

The UK-level figures are broken down in the published tables to provide estimates for the different countries of the UK and English Government Office Regions (GORs).

In 2007 London had the highest estimate of non-UK born residents (2.5 million) in comparison with the other regions of the UK. This meant that 1 in 3 London residents were born outside the UK. This compares with around 1 in 10 in the South East, and around 1 in 11 in the East of England.

The change in the estimated number of non-UK born residents who lived in each region of the UK between 2004 and 2007 can be seen in Map 1. This map shows that each GOR and country of the UK has seen an estimated increase of non-UK born residents of at least 14 per cent over the four year period. The percentage increase in London, the South East and the North East has remained small (under 20 per cent). London and the South East already had relatively high levels of non-UK born residents in 2004 . The estimated number of non-UK born residents in London increased from 2,168,000 in 2004 to 2,474,000 in 2007; and the number in the South East increased from 667,000 to 786,000 .

The largest percentage increases in the UK occurred in the East of England ( 34 per cent), North West (32 per cent), and the East Midlands (32 per cent).

The percentage of non-UK born residents in Northern Ireland increased by 33 per cent, but started from a low base; from an estimated 71,000 in 2004 to 95,000 in 2007.

Map 2 shows the most common non-UK country of birth in each region of the UK in 2004 and 2007.

India was one of the five most common non-UK countries of birth in each country and region of the UK throughout the 2004 to 2007 period. The estimated number of Indian born residents also increased in each region (see Table 4). In 2004 India was the most common non-UK country of birth in the East Midlands, West Midlands and London, and by 2007 it was also the most common in the South East, becoming more numerous than Republic of Ireland born residents who remained at a roughly constant level over the four years.

Pakistan was consistently the most common non-UK country of birth in the North West and in Yorkshire and The Humber between 2004 and 2007. The estimated number of Pakistani born residents increased from 46,000 to 51,000 in the North West, and from 59,000 to 72,000 in Yorkshire and The Humber.

The East of England's most common non-UK countries of birth changed noticeably over the four year period. The size of the Irish Republic born population remained constant throughout the period at around an estimated 37,000; however, the number of both Polish and Indian born residents increased from 5,000 to 41,000 and from 29,000 to 39,000 respectively. In 2004 and 2006 the Republic of Ireland was the most common non-UK country of birth in this region, but in 2007, both Indian and Polish born residents were more prominent, and Poland became the most common non-UK country of birth.

\section{Table 4}

Number of Indian born residents in UK by country and GOR, 2004 and 2007 (thousands)

\begin{tabular}{|c|c|c|c|c|}
\hline & \multicolumn{2}{|c|}{2004} & \multicolumn{2}{|c|}{2007} \\
\hline & Estimate & $\mathrm{CV}$ & Estimate & CV \\
\hline England & 478 & a & 581 & a \\
\hline Wales & 5 & c & 9 & c \\
\hline Scotland & 15 & c & 18 & c \\
\hline Northern Ireland & 4 & $d$ & 6 & $d$ \\
\hline North East & 7 & c & 10 & c \\
\hline North West & 32 & $b$ & 43 & c \\
\hline Yorkshire and The Humber & 28 & $c$ & 33 & c \\
\hline East Midlands & 52 & $\mathrm{~b}$ & 60 & c \\
\hline West Midlands & 70 & $b$ & 79 & $b$ \\
\hline East & 29 & c & 39 & c \\
\hline London & 190 & $b$ & 227 & $b$ \\
\hline South East & 55 & $b$ & 70 & $b$ \\
\hline South West & 16 & c & 20 & c \\
\hline United Kingdom & 502 & a & 613 & a \\
\hline
\end{tabular}

Notes: totals may not sum due to rounding

Key: CV - coefficient of variation:

a - estimate is considered precise

$\mathrm{b}$ - estimate is reasonably precise

c - estimate is considered acceptable

$\mathrm{d}$ - estimate is not considered reliable for practical purposes

In 2004 Poland was absent from the five most common countries of birth in all regions of the UK. By 2007, it was found in each region, and was the most common in the East of England and Scotland.

Between 2004 and 2007 residents who were born in Poland became more widely distributed across the UK, as can be seen in Figure 2. In 2004, the Polish born were most prominent in London and the South East, whereas in 2007 the proportion of those born in Poland had increased in all other regions, and fallen in these two.

The age distribution of the Polish born residents of the UK also changed between 2004 and 2007. Figure 3 shows the proportion of Polish born in each age group in both 2004 and 2007.

Figure 2

Percentage of Polish residents in each UK country and GOR, 2004 and 2007

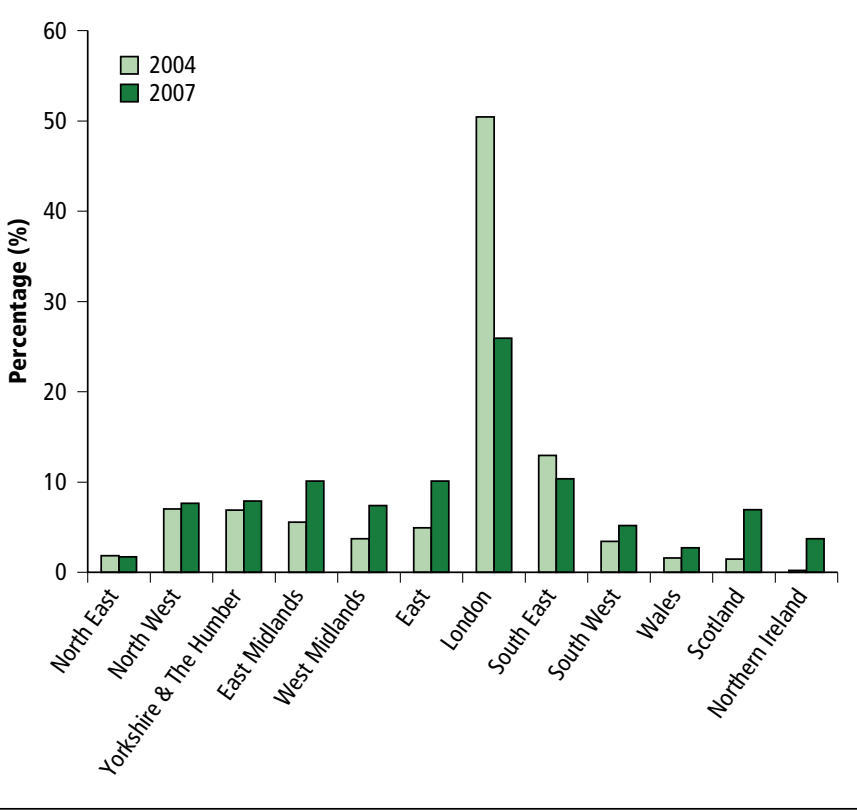




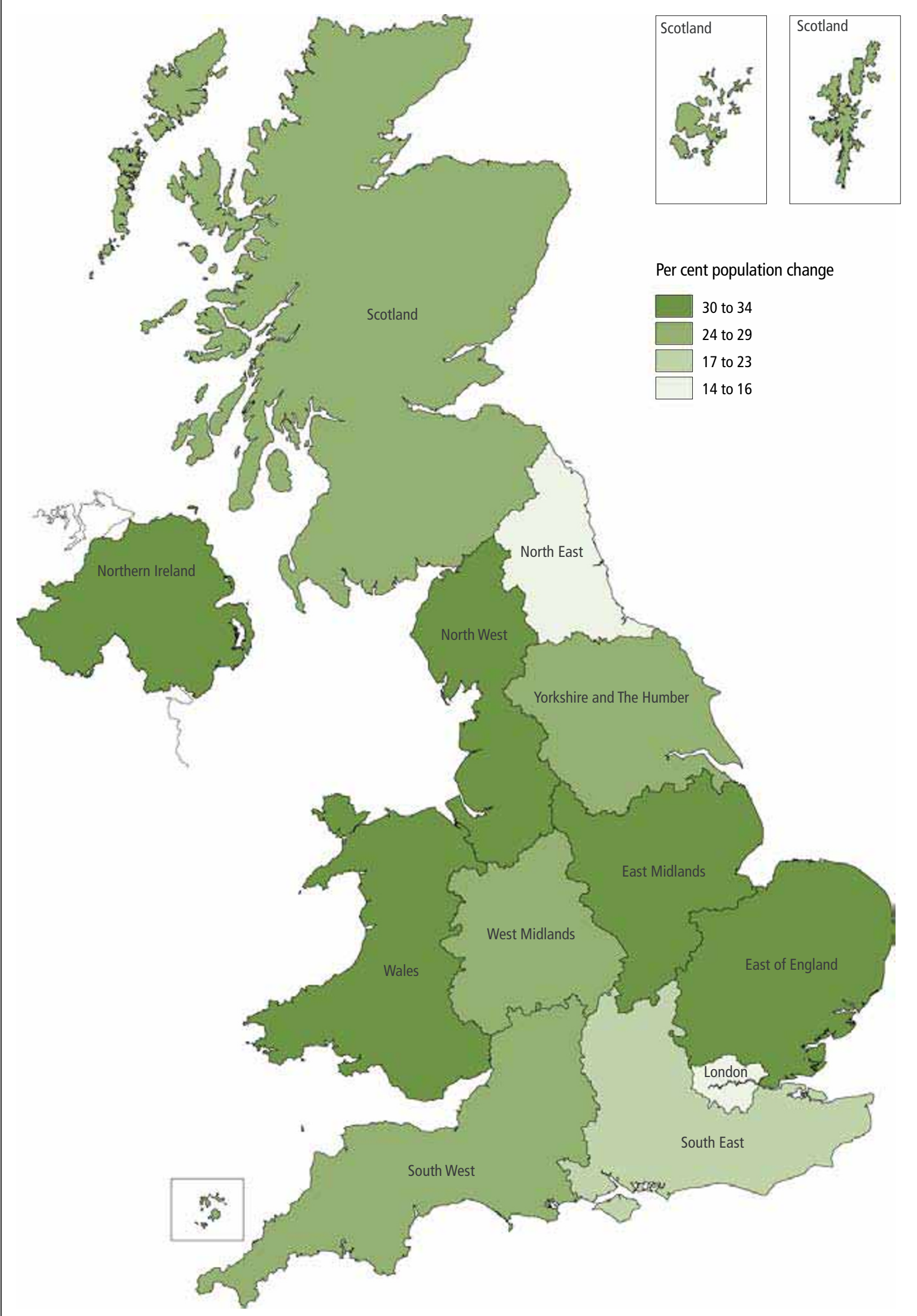




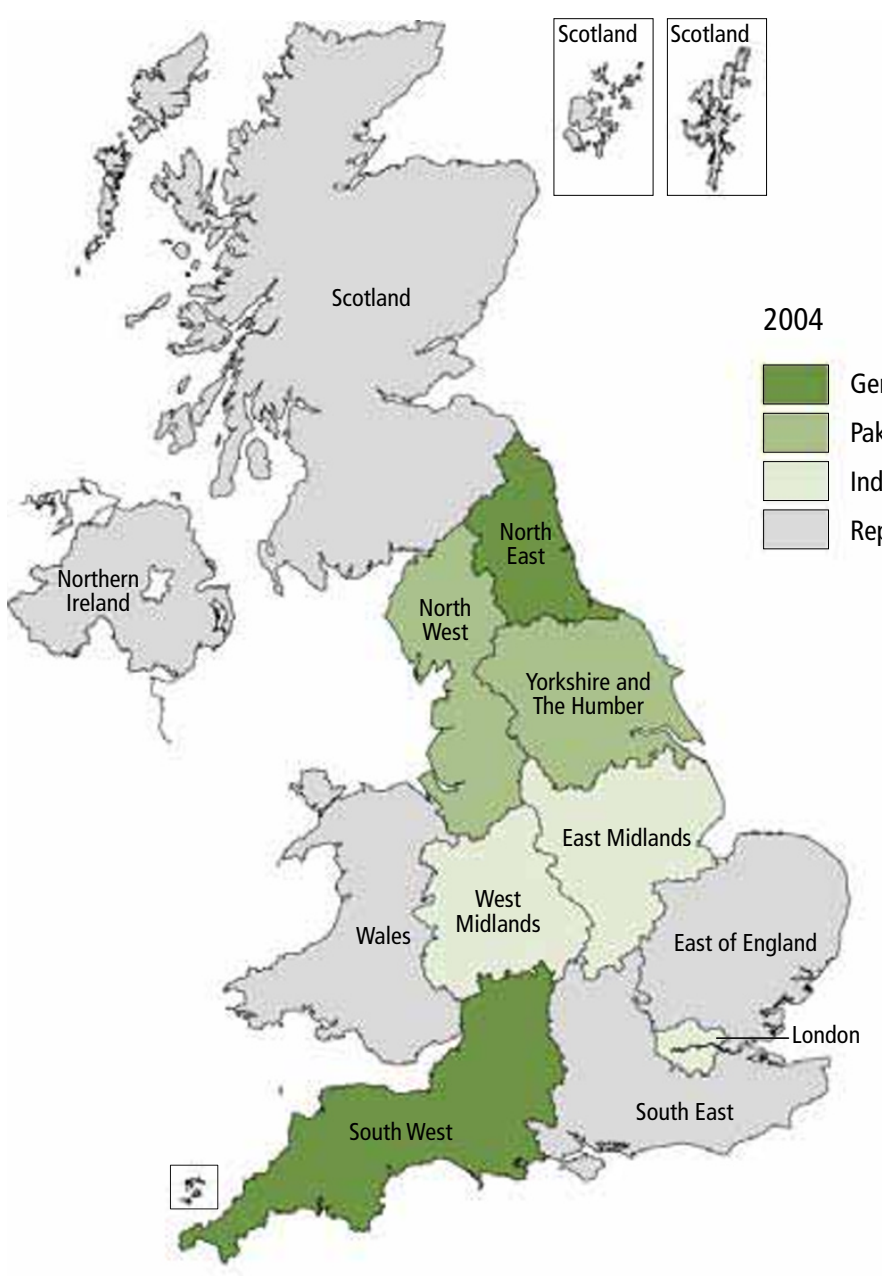

2007

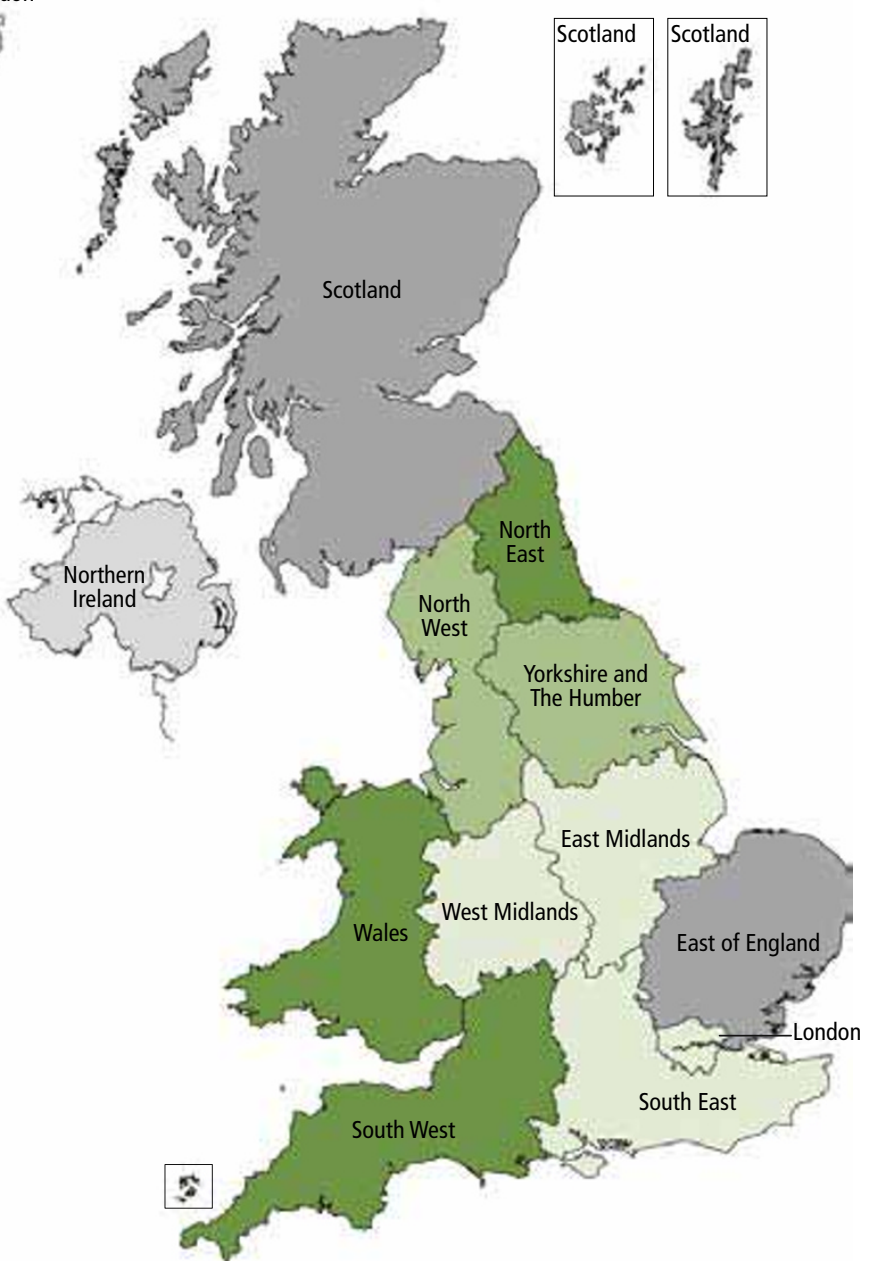




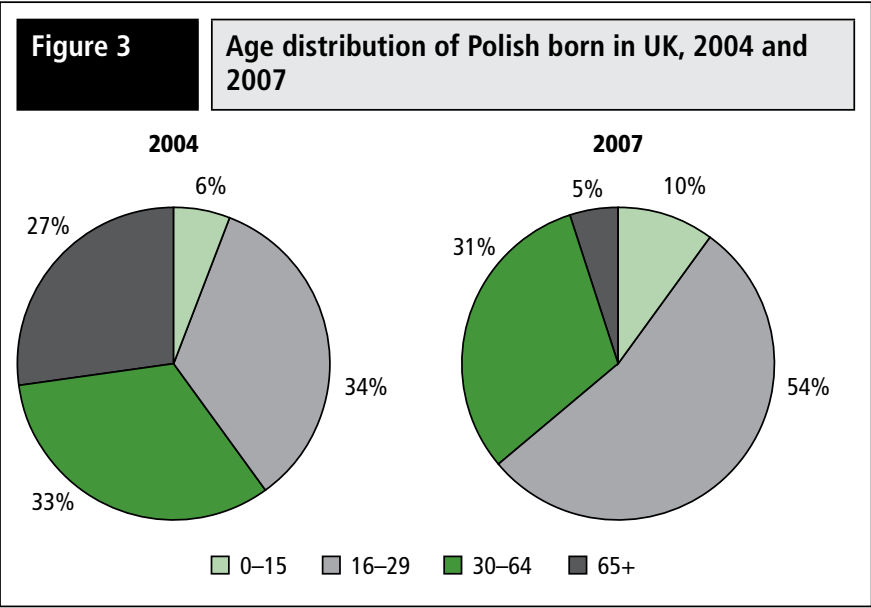

The proportion of 0 to 15 year olds increased by 4 percentage points and the estimated number in this age group increased from 5,000 to 41,000. This increase may be a result of Polish born people migrating to be with their families and settling here.

Those aged 16 to 29 have increased from an estimated 33,000 in 2004 to 220,000 in 2007, and the proportion of all Polish born in this age group also increased by 20 percentage points. The proportion of those aged 30 to 64 who were resident in the UK remained roughly constant (from 33 to 31 per cent), but the estimate increased from 31,000 in 2004 to 124,000 in 2007. These two groups represent those of working age who have migrated to the UK since accession.

The proportion of the Polish born population aged 65 and over decreased dramatically over the four year period, but the estimated number only declined very slightly from 25,000 in 2004 to 20,000 in 2007. Of these Polish born residents, 76 per cent arrived in the UK during the 1940s.

The changing age distribution of people born in Poland who were resident in the UK between 2004 and 2007 is consistent with the age distribution of Polish citizens migrating into the UK over the same four year period as taken from the International Migration series (Box five).

\section{Trends at a lower geographical level}

The published tables at UK and regional level can be broken down to unitary authority, county, metropolitan borough and London borough level. Data at a lower geographical level are not published as they are not reliable.

\section{Box five}

Total International Migration (TIM) presents annual statistics on the flows of international migrants to and from the UK who intend to stay for 12 months or more ${ }^{3}$. The migrant 'stocks' estimates presented in this article cannot simply be combined with the migration flows data in order to calculate the next year's stocks estimates. This is due to definitional differences between the ways in which the data is collected for each purpose. On the other hand, they can be compared to see if the emerging trends are consistent. For example, looking at 2007 TIM figures, the top two non-British citizenships migrating into the UK were Polish and Indian, matching the findings in this article, namely that these two countries are within the three most common non-UK countries of birth of people resident in the UK.

See note 3 for further information about International Migration.

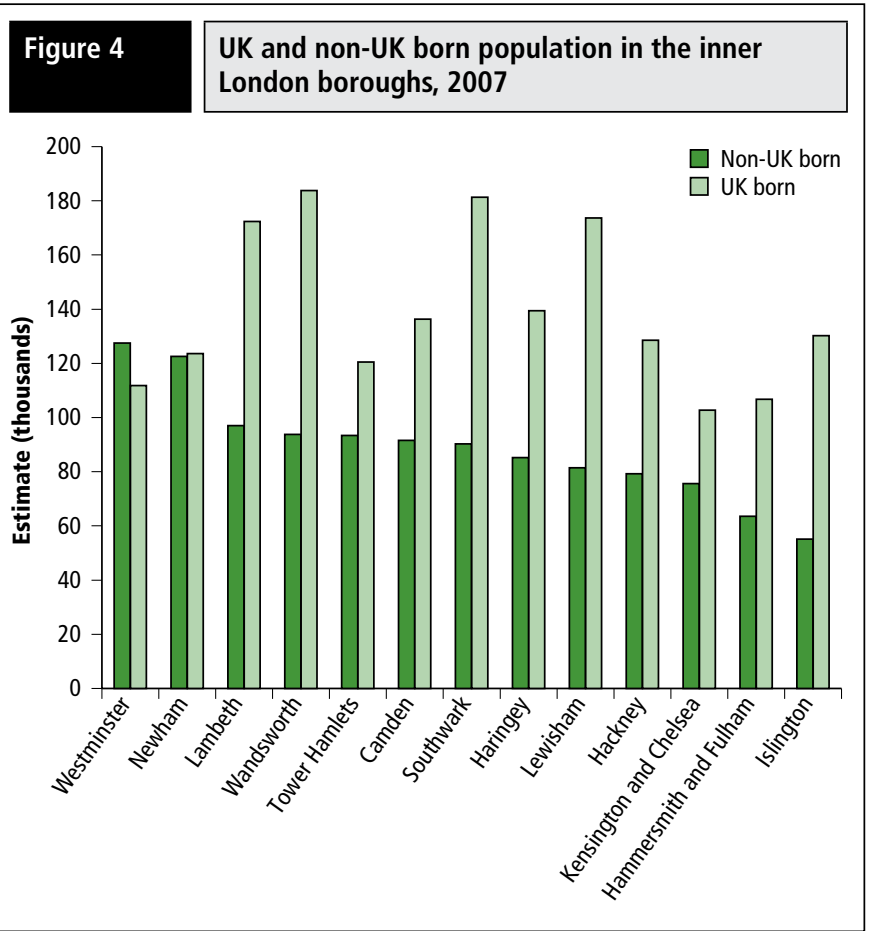

In 2005 Westminster became the first local area in the UK to have a greater non-UK born than UK born population. The most common non-UK countries of birth in Westminster were the USA, Bangladesh, Australia and India. Figure 4 shows the UK and non-UK born population of each inner London borough in 2007.

In 2006 Brent became the second local authority in the UK to have a greater non-UK born than UK born population. The most common countries of birth in 2007 in Brent were India, Sri Lanka, Jamaica and Brazil.

Map 3 shows the most common non-UK country of birth in each London borough in 2007.

Residents born in the same countries appear to live in similar geographical regions of London. For example, people born in India, Pakistan and Bangladesh predominantly reside in parts of north east and north west London. The Nigerian born reside in the east of London, and those born in Turkey live in the north. Those born in the USA have congregated around central London in the inner London boroughs of Camden, Westminster, and Kensington and Chelsea.

In over half of the UK unitary authorities, metropolitan boroughs, London boroughs and counties, the non-UK born population has increased, whereas the estimated number of UK born residents has decreased between 2004 and 2007. Three areas of the UK in which the pattern is most noticeable, and which also have a large population size, are Birmingham, Surrey and Sheffield. The country of birth trends found in these areas are analysed below.

Birmingham is one of the areas in which this is most evident, as the nonUK born population increased by 30 per cent, but the size of the UK born population decreased by 4 per cent. The changes in the composition of this population by country of birth can be seen in Table 5 .

The UK born population in Birmingham has decreased from an estimated 831,000 in 2004 to 800,000 in 2007 . The main country of birth which contributed to the increased size of the non-UK born population is Pakistan, which increased by an estimated 20,000 over the four year period. 


\section{Map 3}

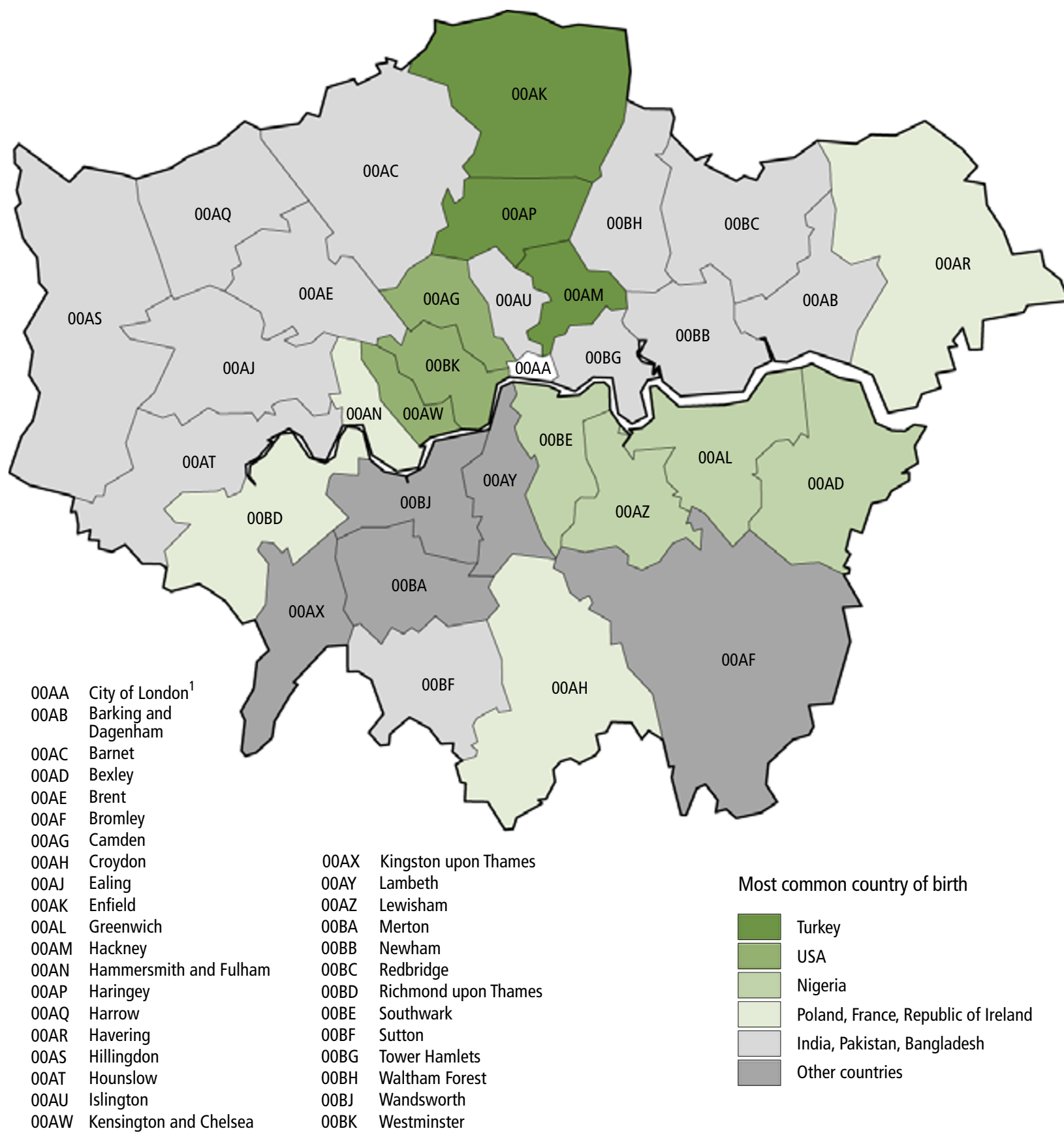

Note: The 'Other Countries' grouping refers to Jamaica, Australia, South Africa and South Korea. The 13 countries therefore shown on this map consist of the most common country of birth found in each borough.

1 No data available for City of London.

The non-UK born population of Surrey increased by an estimated 32,000 between 2004 and 2007. This increase was due to people settling in the UK who were born both in the EU and those countries outside the EU. The EU born residents increased overall by an estimated 12,000 (this increase was not a result of the accession of Romania and Bulgaria to the EU on 1 January 2007). The non-EU countries of birth increased overall by an estimated 20,000 , and countries predominantly contributing to this increase were India, Hong Kong, Canada and South Africa.

Like Surrey, the size of the UK born population decreased in Sheffield, and the size of the non-UK born population increased by 21,000 . Of this increase, one-third were EU born residents (none of this increase was due to the accession of Bulgaria and Romania), and the rest were born in nonEU countries. The individual EU countries of birth which contributed most to this increase were Slovakia and Poland. The individual non-EU countries of birth which contributed most to this increase were Pakistan, India and China.

\section{Conclusion}

The analysis undertaken in this article provides an insight into the changing composition of the UK population between 2004 and 2007 when exploring country of birth. The size of the non-UK born population 


\section{Table 5}

Birmingham population by country of birth, 2004 to 2007 (thousands)

\begin{tabular}{l|r|r|r|r|r|r|r|r}
\hline Country of birth & \multicolumn{2}{|c|}{2004} & \multicolumn{2}{|c|}{2005} & \multicolumn{2}{|c|}{2006} & \multicolumn{2}{|c}{2007} \\
\hline & Estimate & CV & Estimate & CV & Estimate & CV & Estimate & CV \\
\hline UK & 831 & a & 827 & a & 800 & a & 800 & a \\
Non-UK & 153 & b & 165 & b & 195 & b & 199 & b \\
Republic of Ireland & 17 & d & 16 & d & 15 & d & 14 & d \\
EU13 & 9 & d & 9 & d & 6 & d & 9 & d \\
A8 & : & d & 2 & d & 7 & d & 6 & d \\
Pakistan & 31 & C & 42 & c & 46 & c & 51 & c \\
India & 19 & d & 22 & c & 26 & c & 23 & d \\
Jamaica & 12 & d & 14 & d & 15 & d & 15 & d \\
Bangladesh & 11 & d & 9 & d & 13 & d & 14 & d \\
Other & 53 & c & 50 & c & 66 & c & 67 & c \\
Total & 985 & a & 992 & a & 996 & a & 999 & a \\
\hline
\end{tabular}

Notes: totals may not sum due to rounding

$$
:=\text { no data }
$$

Key: CV - coefficient of variation:

a - estimate is considered precise

$\mathrm{b}$ - estimate is reasonably precise

c - estimate is considered acceptable

$\mathrm{d}$ - estimate is not considered reliable for practical purposes

is increasing while the UK born population has remained mostly constant. This increase is in part due to the accession of the A8 countries in 2004 to the European Union, and also from the large numbers of people resident in the UK from countries such as India and Pakistan.

The Polish born residents became more widely distributed across the UK, with a lower proportion found in London in 2007 and a greater proportion found in other regions. London still had the greatest number of non-UK born residents overall, as one in three residents were born outside the UK.

In 2005 Westminster became the first place in the UK to have a greater non-UK than UK born population. It was also found that residents who are born in the same countries tend to reside in similar locations within London; for example, those born in India live in the north east and north west of the city. Many places in the UK have seen the size of their non-UK born population increase and their UK born population decrease. This is most noticeable in Birmingham, Surrey and Sheffield.

\section{Key findings}

- The size of the non-UK born population has increased by 1.1 million between 2004 and 2007

- The most common non-UK country of birth consistently between 2004 and 2007 was India. This made up around 10 per cent of the non-UK born population each year

- The size of the A8 born population in the UK increased by 423,000 between 2004 and 2007

- Poland was the third most common non-UK country of birth in 2007, up from 12th in 2004

- In 2007 one in three London residents were born outside the UK

The Annual Population Survey (APS) is used to produce quarterly published tables which provide regular estimates of the composition of the UK population by country of birth and nationality. The tables are available at: www.statistics.gov.uk/StatBase/Product.asp?vlnk=15147

The 2008 calendar year tables are due to be published in August 2009.

Population by country of birth and nationality data is also available separately for Scotland on the General Register Office for Scotland website, available at: www.gro-scotland.gov.uk/statistics/publicationsand-data/population-estimates/population-by-country-of-birth-andnationality-2004-2007.html

If any further information is required, please contact the ONS Migration Statistics Unit at migstatsunit@ons.gov.uk.

\section{Notes and references}

1 Office for National Statistics (2008) Information on the Annual Population Survey is available at: www.statistics.gov.uk/STATBASE/ Product.asp?vlnk=10855

2 Office for National Statistics (2008) Information on the Labour Force Survey is available at: www.statistics.gov.uk/StatBase/Source. asp? lnk $=358$

3 Office for National Statistics (2008) Information on latest UK Total International Migration estimates available at: www.statistics.gov.uk/ STATBASE/Product.asp?vlnk=507 